tions of the previous health organizations and conducted emergency health international work.

The objective of the World Health Organization is defined as "the attainment by all peoples of the highest possible level of health". For the time being, this high aim cannot be realized. Once more, international politics have placed obstacles in the way of world health. The U.S.S.R. and its satellites have withdrawn from the Organization, and the new government of China is not a member. With expenditure on armaments and national health services, there is little money available for helping and subsidizing the public health work of less progressive countries. The main work of the Organization seems, therefore, for the present to lie in epidemic intelligence, the making of international standards and the giving of expert advice, on request, to health administrations on public health matters. If disappointment be felt at this conclusion, when preventive medicine holds so many powerful weapons for the eradication of disease and suffering, it should be remembered that the work of the past hundred years has laid the foundations of international health, that much has been achieved, and that work of this character marks progress on the way to the time when all the nations of the world will unite for the good of mankind.

$$
\text { REFERENCES }
$$

Buchanan, G. S., "International Co-operation in Public Health: its Achievements and Prospects", Milroy Lectures, Roy. Coll. Phys., Jondon, 1934 (Lancet reprint).

Goodman, N. M., "International Health Organizations and their Work" (London, 1952).

MacNalty, A. S., and Mellor, W. F., "Health Recovery in Europe" (London, 1946).

\section{BRITISH WELDING RESEARCH ASSOCIATION}

\section{NEW FATIGUE TESTING LABORATORY AT ABINGTON, CAMBRIDGE}

$\mathrm{M}$

$\mathrm{UCH}$ is already known of the fatigue properties of structural steel and other industrial metals, when tested as simple laboratory specimens. Even so, it is essential to take into account the geometrical and metallurgical notches introduced into structures by welding or other methods of fabrication if fatigue failures are to be avoided. Because of this, the fatigue testing of welded structural components forms an important part of the work of the British Welding Research Association at its Engineering Research Station at Abington, near Cambridge. This work has received new impetus with the completion of a new Fatigue Testing Laboratory, officially opened by Lord Woolton, Lord President of the Council, on June 23. The new laboratory, which has a floor area of $5,000 \mathrm{sq}$. ft., is of technical interest in itself, since it is the first building to be erected for which the plastic design method, originated by Prof. J. F. Baker, professor of mechanical sciences in the University of Cambridge, has been applied. Appreciable economies in steel have been effected thereby, and the architect and consulting engineers have been enabled to produce an resthetically pleasing building in which the steelwork is particularly unobtrusive.

The structural components which are tested come from the oil and power, aeronautical, shipbuilding, automobile and general engineering fields, and it is not surprising, therefore, that three broadly different methods of load application are used. Of these, the method of resonance vibration has been used for some years. The basis of this is the Lanchester oscillator, in which a pair of eccentrically mounted masses are rotated in opposite directions by means of a variable-speed motor, to produce an oscillating force in a given plane relative to the specimen, which is freely suspended at its nodes. When the speed is adjusted to a point near resonance, considerable stresses are set up in the specimen. In one case, fatigue bending tests have been carried out on light box members simulating chassis members in a motorcar, while, at the other extreme, tension/compression loads of +30 tons have been excited in Bailey bridge members, by the addition of masses at either end to establish the correct mode of vibration. Precise control of the induced stresses is important, and is achieved by speed control, using either amplitude of vibration or strain, through a wire-resistance straingauge, as the variable governing the servomechanism.

The resonance method is flexible in its application to varieties of structure, but has the disadvantages of producing only equal tension and compression load-cycles, and a severe size limitation caused by the rate of wear of large oscillators. The Association has therefore acquired two non-resonating machines of 100 tons capacity for installation in the new laboratory. The Losenhausen machine, with mechanical and hydraulic actuation, works at speeds of $100-600$ cycles per min. (compared with more than 3,000 cycles per min. for a resonance machine). An interesting feature is its mounting on twenty-four struts, the Euler crippling load of which has just been exceeded, so that they behave as soft springs, ensuring that no vibrations from the 20 tons mass of the machine are communicated to the foundation. This method of mounting was developed by T. S. Robertson, of the Naval Construction Research Establishment, Rosyth. The other machine was designed by Prof. W. M. Wilson, of the University of Illinois, and is operated by means of an eccentric and a load-multiplying lever. Two specimens may be tested independently and simultaneously in this machine, but only at 100 cycles per minute. Parts for this machine have been made in Great Britain and given to the Association by a number of manufacturers interested in furthering the work of fatigue testing. Both the Illinois and Losenhausen machines make provision for statically preloading the specimen during test, so that load-cycles to the extremes of zero to maximum tension or compression may be applied.

The remaining fatigue-testing machine operated by the Association is concerned with pressure vessels and pipeline components subjected . to internal pressure. This consists of a large-capacity hydraulic pump, together with automatic valve gear designed to apply pressure pulsations from atmospheric to $6,000 \mathrm{lb}$./sq. in. at up to 100 cycles per min.

The method of fatigue testing is attractive, even for structural members which may not be subject to severe pulsating loads during service, because of the searching comparison which may be made between types of weld and methods of design. Proneness to failure through the effect of stress concentration is exposed where static loads would be sustained with full ductility.

In parallel with the full programme of fatigue testing at present being carried out by the staff of the laboratory, studies are being made of the mechanics of crack propagation, the phenomenon which is fundamental to brittle and fatigue structural failures.
A. A. WELLS 